\title{
Cloud Computing-Based Faculty ePortfolio and Evaluation System (COMFORTES)
}

\author{
Belen M. Tapado and Benilda Eleonor V. Comendador
}

\begin{abstract}
The paper promotes adoption of Cloud Computing Services for evaluation of the credentials and information about the credentials submitted by the faculty members for their promotion to higher academic ranks based from the National Budget Circular (NBC) 461 Common Criteria for Evaluation (CCE). The study is intended to be utilized in the State Universities and Colleges (SUCs) in the Philippines. COMFORTES was developed using Open Source Technologies of PHP, MySQL and WAMP Server. Prototyping approach in the development of the system was employed. The system initially adopts a free cloud computing service, however, the full implementation of the system would require subscription to a cloud service provider since huge data for faculty records will be stored. Utilizing the system would enable a fast, fair, accurate and consistent faculty evaluation. A strong faculty profile would mean quality offering of courses. Merit and promotion that was based on objective evaluation would serve as morale booster for faculty members.
\end{abstract}

Index Terms-Cloud computing, eportfolio, faculty evaluation system.

\section{INTRODUCTION}

In the teaching and learning environment, a teacher should be a repertoire of best teaching practice. Teachers should let the students engage in activities that will enable them to acquire knowledge and skills and at the same time develop worthwhile values and attitudes [1]. Learning happens if there is response and there is transformation of learners from being passive to active. Emphasis therefore is given to teacher's personal and professional ability. To measure the teaching effectiveness, tracking and monitoring of the teacher's performance is inevitable. Considerations as to teacher's level of knowledge, teaching power, instructional effectiveness, executive ability, management skill, professional responsibility, ethics and interpersonal relationships are gauged to evaluate the teacher's performance. Teacher products such as instructional materials prepared, student files and grading patterns are also looked into.

The gauging, quantifying, qualifying of the teacher's service contribution to their students, field of specialization and university that they are working is happening not just in the Philippines but also in other countries.

In an institution of higher learning like the colleges and

Manuscript received February 1, 2016; revised April 14, 2016. This work was supported in part by the Polytechnic University of the Philippines.

B. M. Tapado is with Polytechnic University of the Philippines, Manila, Philippines. She is also with Catanduanes State University, Philippines (e-mail: bmtapado@ gmail.com).

B. E. V. Comendador is with the Polytechnic University of the Philippines, Philippines (e-mail: bennycomendador@yahoo.com). universities in the Philippines, faculty members duties are not only focused to instruction but also to the development of teaching resources to augment his/her teaching, doing research to improve his teaching process, extending research results as his/her extension services to the community and doing creative works to add to the pool of knowledge in the society.

Since Information Technology is indispensable in any field of endeavor, its use in facilitating the teaching and learning process is also inevitable. Information system is also indispensable in schools and educational activities hence information systems should also be used to facilitate instruction and test for the effectiveness of students and faculty alike.

Faculty members in state universities and colleges subject for evaluation of professional qualifications and credentials such as their educational attainment, training and seminars attended, researches and instructional manuals written and extension programs participated in once in every three years through the National Budget Circular (NBC) No 461 s. 1998 of the DBM [2]. This is done through the Common Criteria Evaluation (CCE) and Qualitative Criteria Evaluation (QCE) so that if they garner the right amount of points, they could be promoted to higher academic ranks.

Faculty member's professional qualifications and credentials should be tracked not just using papers, pencils and keeping bulk of copies of such evidences on their folders. It will be better if they are tracked electronically and their credentials be rated through the corresponding points based on the approved point-system in the CCE. This was prescribed by Philippine Association of State Universities and Colleges (PASUC) through its NBC 461 Guidelines.

Such bulk of data will be kept through a database that runs through a cloud computing services since it will be more economical to pay for a running system that uses cloud computing service than letting the school purchase the hardware and software necessary for the design, development, implementation and maintenance of the system. Cloud Computing is the latest trend or standard for launching and providing services across the Internet. It is the usual choice of the companies because they will only pay for the number of hours or minutes of the services made and the resources utilized [3].

In a learning process, portfolio is defined as an assembly of proofs or facts that are gathered together to show a person's learning journey for a period of time and to exhibit his learning aptitudes [4]. It is a collection of student's work that demonstrates the activities done by the student's, their efforts exerted, progress, and achievements relative to a particular subject matter [5]. ePortfolio on the other hand is a collection 
of information and digital artifacts that shows the development or evidences of achievement of learning objectives, the outcomes of the student's learning, and the skills or competencies acquired by the students also relative to a subject matter[6].

In this study, keeping track of faculty's records of credentials is termed as "ePortfolio" and letting the system specify points for each submitted credentials which are prescribed in the $\mathrm{CCE}$ is considered as "Performance Evaluation System".

The manner of keeping track of faculty records and assigning points for each credentials submitted which is termed as "faculty evaluation" will be done electronically. The system to do this was developed and dubbed as "COMFORTES". Since there are more than hundreds or thousands of faculty member's records that will be stored in the system, data mining technique was employed. Through data mining [7] faculty member's credentials and other evidences of achievements are being stored and reports could be generated and accessed through the system. Faculty profiling for quality assurance such as program accreditation, International Organization for Standards (ISO), center of development or excellence would be an easy task. Likewise, reluctance of faculty to submit for evaluation would be minimized or avoided.

The reliability of the data stored in the system could be ensured by the cloud computing services. This technology would be working at its best especially for those areas that are frequently visited by typhoons and other calamities like earthquakes, floods and tsunamis as in the case of Catanduanes, an island which is situated in a typhoon belt area in the Philippines. Since files stored in the clouds are not necessarily located in the geographic location of the system but in the cloud computing server that the institution will subscribe with, in the future. The data would be safeguarded from the calamity and the faculty members could access their data anywhere provided there is an internet connection.

It is due to the above premises that the proponent has developed and tested the cloud computing-based faculty eportfolio and evaluation System (COMFORTES).

It is an aim of the researchers that if this system will be fully implemented in schools, especially state universities and colleges all over the country, monitoring of faculty's merit and promotion could be an easy and hassle-free activity on the part of the school's administrator. Likewise, the reports generated by the system could be an aid for the decision-making process in the academe regarding the welfare of the faculty.

Although institutions also need to recognize that the process of implementing an electronic portfolio system is a long-term one, and it may take several years before the full benefits will be seen, implementation of it is imperative to facilitate the tracking of faculty performance for institutional and national evaluation.

The need for assessing the significant contribution of faculty members in schools and the scarcity of an automated systems for evaluating faculty members and utilizing the services of cloud computing is a gap observed that made the researchers embark on the present study.

\section{THE SYSTEM}

\section{A. System Architecture}

Fig. 1 depicts the system architecture of COMFORTES. Data sources were the inputs for the system. These data sources are the information, reports and underlying issues regarding the evaluation system done in the State Universities and Colleges particularly as regards garnering of CCE points. Faculty members, Verifier and System Administrator are the users of the system. The components of COMFORTES are the Web Server, the Graphical User-Interface or the Front-End that serves as the communication between the users of the system the hardware components of the system. Such front-end is connected to the Back-end which is the Database Server (MySQL). The system has a two-way communication process with the Cloud Computing services.

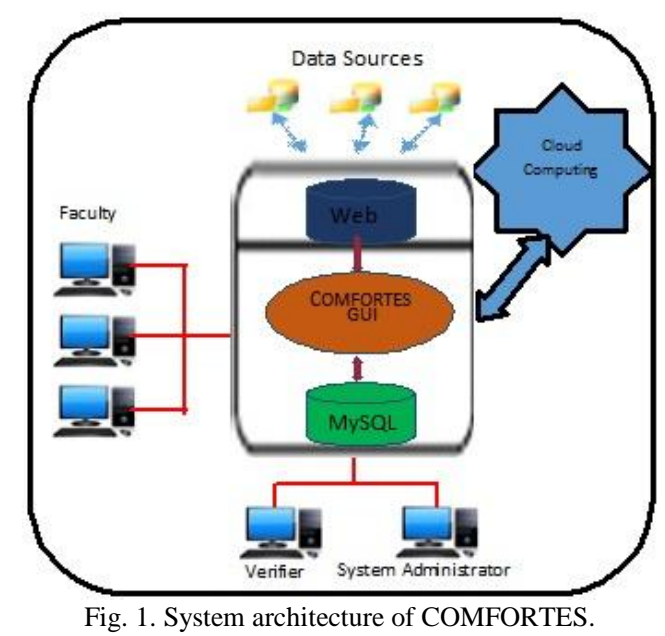

\section{B. The Development of the System}

The study designed, developed and made the user assess the information system about the faculty e-portfolio and evaluation. This study was the automation and assessment of the faculty evaluation based on the Common Criteria for Evaluation (CCE) of the National Budget Circular (NBC) 461 for Philippine Association of State Universities and Colleges (PASUC). The evaluation is composed of three (3) parts. Part I is about the "Educational Qualification" of the faculty which focuses on the bachelor, and post-graduate education acquired by the faculty; Part II is concerned with the "Experience and Length of Service which includes the work experiences and academic designations" and Part III is on the "Professional Development, Achievement and Honors" attained by the faculty which includes the training attended, creative works, researches done, consultation and any other academic and professional activities by which the faculty is involved with.

The system was developed using Open Source Technologies of PHP, MySQL and WAMP Server. Graphical User Interface was designed using Adobe Photoshop. MySQL served as the back-end of the system. PHP had been employed as the front-end of the system. Wamp Server is Window-based web development platform that served as a place to write codes and develop COMFORTES programs. In using the Wamp Server, the scripts were tested locally without having to upload them through internet. The security of 
maintaining the files locally were established before they are being launched through cloud-computing service. This tool made the developer develop the system without being connected to the internet.

Prototyping development approach was employed having the users of the system being involved before, during and after the development of the system. Faculty members and the verifier were involved in the course of development. Suggestions were solicited from them once in a while to ensure that all the requirements of these users were integrated in the developed system. This method was used in this approach: 1) meeting with the concerned individuals regarding faculty evaluation process, observation and interviews; 2) preliminary analysis and development of the system; 3 ) coordination with the faculty members and school heads and other concerned people of the organization while developing the system and soliciting for their suggestions for improvement - this also entails developing the prototype of the system for their evaluation; 4) integrating the suggestions made by the faculty evaluation experts and other users of the system 5) finalizing the system and its implementation, user's training and technical documentation; 6) revisions for the improvement, enhancement, and expansion of the system.

The submission of the documents to the system by the faculty members would be stored in the Dropbox service [8]. This service works by keeping identical copies of selected files on the user's computer and Dropbox's cloud-based storage system, and automatically synchronizing them over an encrypted Internet connection. Dropbox was the choice because aside from being availed for free service, it is easy and convenient to use since it followed the same conventions that people already use to save files, create folders, and move stuff around on their computers. Dropbox data will appear in the folder created [9].

Testing of the system was done at the Catanduanes State University (CSU), in the Philippines using its Local Area Network and Wireless Internet connectivity. The communication, coordination and interconnection of the PC units for system use were done using this network.

The features of the system are as follows: 1) Capturing of the faculty profile; 2) Creating ePortfolio of the faculty members; 3) Generating assessment points based on the criteria set through NBC 461; 4) Generating required reports.

\section{The Functionality of the System}

COMFORTES functions as follows: 1) once the system administrator granted username and temporary password to the faculty member, the faculty member logs-in in the system; 2) once log-in is successful, faculty member can supply information about their profile and creates permanent password (this is done only once), then they could upload a scanned document in the system (e.g. certificate of participation for the seminar attended). The document uploaded should be in .pdf format (any number of documents for each category could be uploaded provided it is within the rating period specified); 3) faculty member supplies the necessary data about the submitted document to the system; 4) the system evaluates the document submitted and the data inputted to the system; 5) the system generates an initial assessment score for the submission made (basis of scoring will be NBC 461 CCE points); 6) verifier (school's authorized committee on faculty evaluation) evaluates the submissions made by the faculty as well as the initial assessment score generated by the system; 7) once evaluated by the verifier, final assessment score is generated and only the verifier has the right to make some changes in the assessment score; 8) an evaluation report will be generated by the system for submission to the zonal center for verification and official printout that will serve as basis for the promotion of the faculty member to the next higher academic rank. Below is the system flow of COMFORTES:

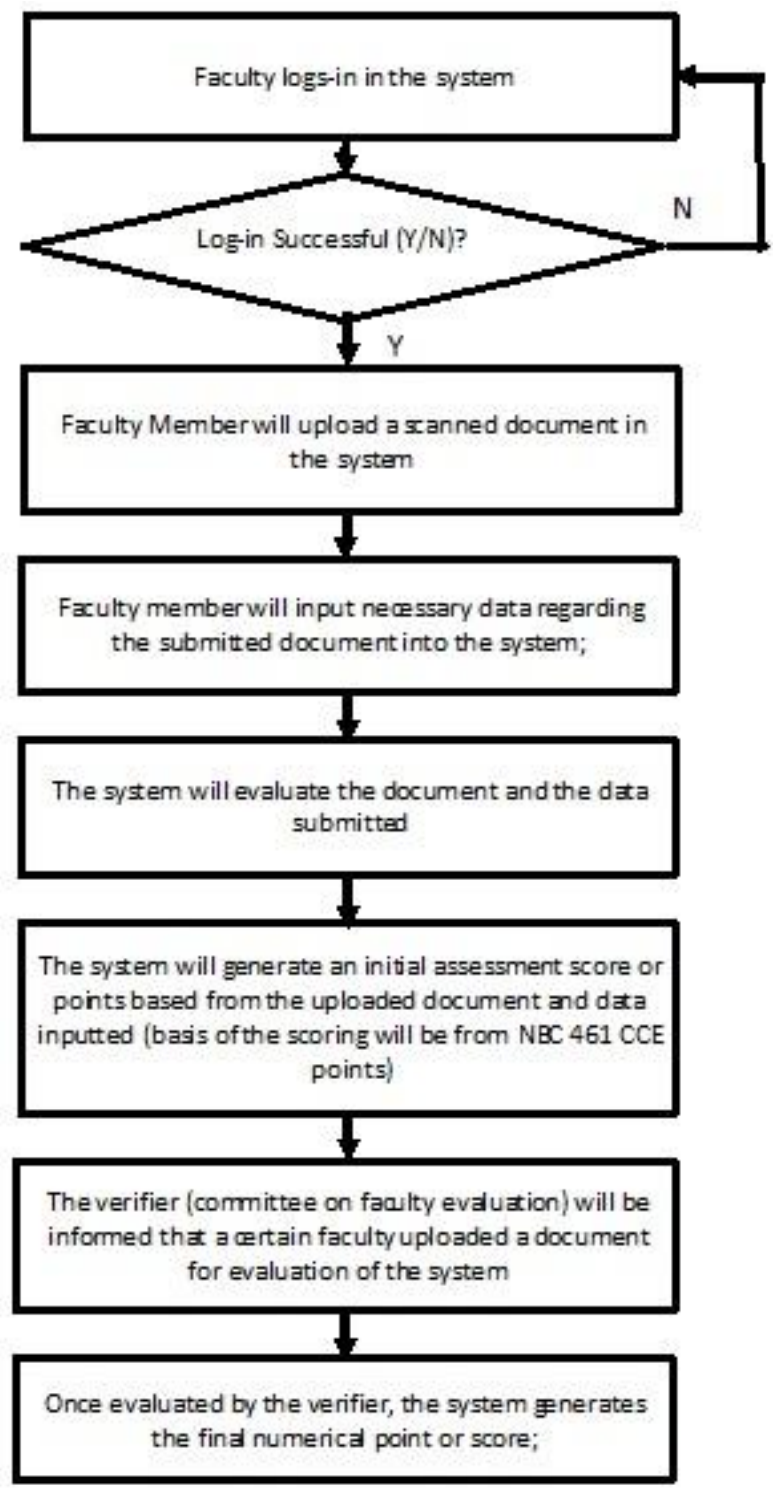

An evaluation report will be generated by the system

Fig. 2. System flow of COMFORTES

\section{RESEARCH METHOD AND TECHNIQUES}

The study explored the concepts, theories, methodologies and technologies in designing the Faculty ePorfolio and Evaluation System.

The study endeavored to answer the following questions: 1) What is the level of agreement of the respondents concerning the issues with regard to the existing faculty evaluation? 2) 
What are the respondent's level of acceptance on COMFORTES in terms of: a) functionality; b) reliability; c) usability; d) efficiency; e) maintainability; f) portability? 3) What are the respondent's level of acceptance on the effects of the system being proposed to the institution?

The descriptive and developmental methods of research were adopted in this study through the actual development and assessment of COMFORTES in terms of acceptance and its effect to the institution where it was pilot tested. The attributes used to test the Level of Acceptance of the system was based from the Software Quality Characteristics of ISO 9126-1 [10].

The questionnaire was utilized as data gathering instrument in this study. The responses were elicited from the 121 respondents.

Descriptive statistics of frequency count and weighted mean were utilized to interpret the data. The data were described in terms of their quantitative and qualitative ratings.

The paradigm of this study is depicted in Fig. 3. This paradigm followed the input-process-output model of the system theory together with evaluation/feedback wherein improvements to the system was done through some suggestions given.

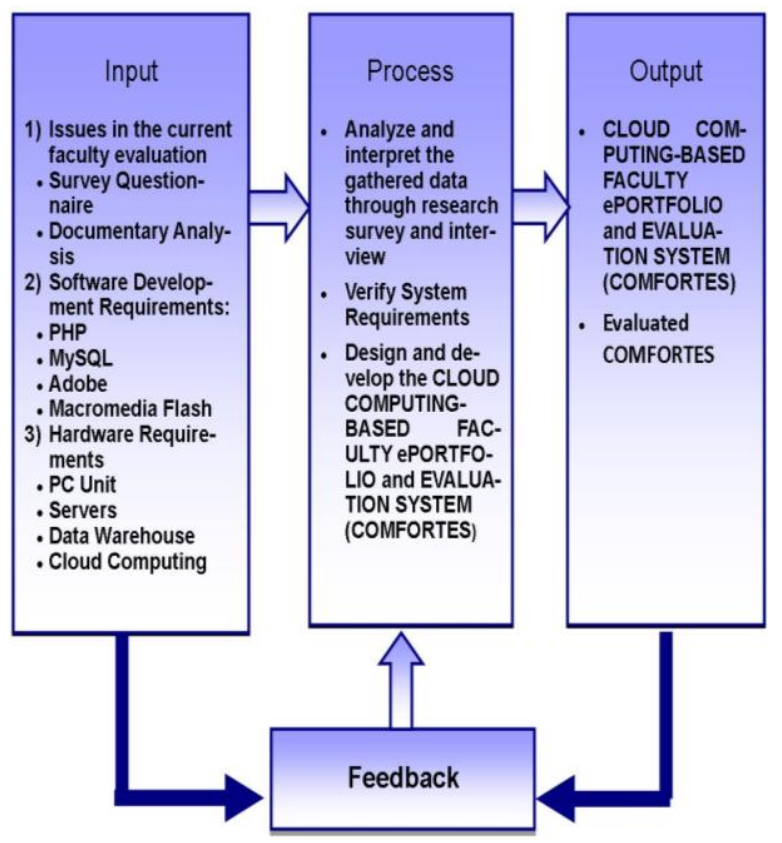

Fig. 3. Conceptual paradigm of COMFORTES.

On the input column are the information, reports and underlying issues regarding the evaluation system done in the State Universities and Colleges particularly as regards garnering of CCE points.

On the process column is the methodology and the manner of analysis that were used in the study on the development, implementation and the survey and analysis of the respondents' responses and the perceptions of the faculty members about the proposed system.

Finally, the output contains that actual evaluation and improvements on the system based on the suggestions of users.

The development of the system followed the following process: a) Conceptual Modeling of COMFORTES - this involved gathering of information about the data needed for the design of the system; b) Gathering of User's Requirements for the system- this involved observation, interviews and document review about the existing process of faculty evaluation and the difficulties in the existing system; c) Analysis and Technical Specification of the System-the data gathered from the users of the system has been analyzed and transformed into technical specifications. Models or prototypes of the system has been developed in this stage for the approval of the users; d) Systems Design- this step involves actual coding of the program using application development software (e.g. PHP, MySQL and Wamp Server); e) Interface Design -this step involved actual architectural design of the system as regards the graphical user interface or the communication part of the system between the user and the system; f) Database Design -this step involved the actual design of the database (storage, organization and accessing of data) of the system. Database involves organizations and connections (relations) of tables containing records of faculty submissions; g) Pilot Testing of the New System -this step involves actual installation and evaluation of the software; h) Systems Installation and Implementation-this step involves actual installation and implementation of the system; i) User Evaluation of the System -this step involves evaluation as to acceptance and observation of the effects of the system to the institution.

\section{RESULTS AND DISCUSSION}

The study was conducted to determine the underlying issues on the conduct of faculty evaluation in a state university of the country, generate faculty ePortfolio, enable a computerized faculty evaluation and assess the level of acceptance and effect of implementing the system in the institution.

The research instrument made use of a 5-point Likert Scale of 5, 4, 3, 2 and 1, ( 5 being the highest and 1 being the lowest) to measure the level of agreement on the issues raised, level of acceptance to the system level of assessment of the effects of the system. The scale is useful for gathering the respondent's feelings, opinions and attitudes (Brown, 1998) [11].

TABLE I: RESPONDENT'S LEVEL OF ACCEPTANCE ON COMFORTES

\begin{tabular}{lcl}
\hline \hline Criteria & Mean Response & Interpretation \\
\hline Functionality & 4.26 & Highly Acceptable \\
\hline Reliability & 4.44 & Highly Acceptable \\
\hline Usability & 4.31 & Highly Acceptable \\
\hline Efficiency & 4.40 & Highly Acceptable \\
\hline Maintainability & 4.30 & Highly Acceptable \\
\hline Portability & 4.35 & Highly Acceptable \\
Overall Mean & 4.34 & Highly Acceptable \\
\hline \hline
\end{tabular}

The first question posed in this study is "What is the level of agreement of the respondents concerning the issues with regard to the existing faculty evaluation?" Of the 13 issues 
raised, the overall rating that was given by the respondents was 3.90 which could be rounded-off to " 4.0 ". This means that the faculty members "agree" on the issues raised as regards faculty evaluation. It could be inferred that the respondents share the same sentiments with the researchers that transparency, accuracy and reliability in the evaluation process were not properly observed.

The second question presented in this study was "What is the level of acceptance on COMFORTES in terms of: (a) functionality; (b) reliability; (c) usability; (d) efficiency; (e) maintainability and (f) portability?" The responses of the respondents were summarized in Table I.

Six out of eight indicators for the level of acceptance in terms of functionality were rated 5 or "Highly Acceptable" by the respondents. All of the indicators for the level of acceptance which are reliability, usability, efficiency, maintainability and portability were rated 5 or "Highly Acceptable". The average rating for each attribute were reflected under "Mean Response" column in Table I.

It could be gleaned from Table I that the overall mean for the respondents' level of acceptance on COMFORTES is 4.34 which is interpreted as "Highly Acceptable". It could be deduced that faculty members believe that automation of the system for faculty evaluation would generate accurate results and faculty members would gain confidence that the evaluation conducted is trustworthy.

The third question answered in this study was "What is the respondent's level of assessment on the effects of the system to the institution?" The respondents gave an overall rating of 4.32 which means "Very Strong" positive effects to the institution.

\section{CONCLUSION}

Based on the evaluation made by the respondents on the system, the following conclusions were drawn: Faculty members agree that there are issues raised regarding NBC 461 faculty evaluation and automating the process gained a "Highly Acceptable" response and yield a "Very Strong" positive effects to carry out faculty evaluation process in the institution. Further, it is recommended that the following measures should be employed: (a) awareness campaign and training on the adoption and utilization of COMFORTES in the institution as a tool in evaluating faculty should be done. Likewise full support of the school administration on the implementation and maintenance of the system is a necessity; (b) the design and functionality of the system should be constantly improved through system maintenance to make them more user friendly and be adopted to the demands of the emerging technologies. Likewise funds should appropriated for periodic upgrading of the system; and (3) the manual system of faculty evaluation should be totally replaced with COMFORTES for evaluating faculty members to encourage the trust and confidence of the faculty to submit themselves for faculty evaluation. It is also necessary that the system could be improved, expanded and maintained to cope up with the demands of time and technology. The system could also be linked to other information systems in the school for an enterprise information system.

\section{ACKNOWLEDGMENT}

The authors acknowledge their indebtedness for the valuable insights, considerations, suggestions, recommendations and invaluable efforts of those persons who helped improve this study starting from conceptualization until presentation and publication.

\section{REFERENCES}

[1] Salandanan, G. G., Methods of Teaching. Quezon City, Metro Manila: Lorimar Publishing Co., Inc 2003, pp. 5-8.

[2] Common Criteria for Evaluation Spedific Guidelies, National Budget Circular (NBC) 461 dated June 1, 1998, Department of Budget and Management, Malacañang, Manila.

[3] Zhang, Q., Cheng, L., \& Boutaba, R. (2010). Cloud computing: state-of-the-art and research challenges. Journal of internet services and applications,1(1), 7-18.

[4] Darling, L. "Portfolio as Practice: The Narratives of Emerging Teachers. Teaching and Teacher Education", 2001, 107-121.

[5] L., P. F., Paulson., P. R., \& Meyer, C. A. What Makes a Portfolio a Portfolio? Educational Leadership, 60-I. S. Jacobs and C. P. Bean, "Fine particles, thin films and exchange anisotropy," in Magnetism, vol. III, G. T. Rado and H. Suhl, Eds. New York: Academic, 1991, pp. 271-350.

[6] What is an ePortfolio? (n.d.). Available: http://www.eportfolios.ac.uk/definition

[7] What is Data Available: http://www.anderson.ucla.edu/faculty/jason.frand/teacher/technologie s/palace/datamining.htm.

[8] What is a Dropbox? whatisdropbox.com: Available: http://webcache.googleusercontent.com/search?q=cache:http://whatis dropbox.com/

[9] What is Dropbox? Dropbox in 30 minutes: The Guide. Available: http://dropbox.in30minutes.com/what-is-dropbox/

[10] ISO 9126 Software Quality Characteristics, An overview of the ISO 9126-1 software quality model definition, with an explanation of the major characteristics. Available: http://www.sqa.net/iso9126.html

[11] Brown Likert Scale: Measurement of Attitudes, Available:http://www.brown.ndirect.co.uk.

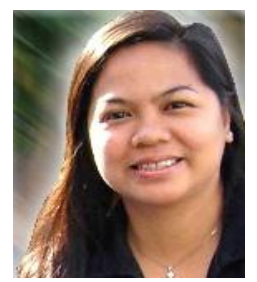

Belen M. Tapado is from San Andres, Catanduanes, Philippines. She was a graduate of bachelor of science in computer engineering at the Polytechnic University of the Philippines in 1991 and earned her master of science in management major in public administration at the Catanduanes State University in 2002. She is presently a candidate for graduation for master of science in information technology (MSIT)

from the Polytechnic University of the Philippine Open University.

She is connected at the Catanduanes State University in the Philippines and presently holding a rank of associate professor III. She is also designated as research coordinator of the College of Information and Communications Technology at the Catanduanes State University.

She is a member of Philippine Computer Society and Philippine Schools, Universities, and Colleges Computer Education and Systems Society (PSUCCESS), Philippine Society of Information Technology Educators (PSITE), Philippines Association of Researchers and Statistical Software and IAMURE Multidisciplinary Research Organization. She is also a member of the pool of Accreditors of the Accrediting Agency of Chartered Colleges and Universities in the Philippines, Inc. (AACCUP).

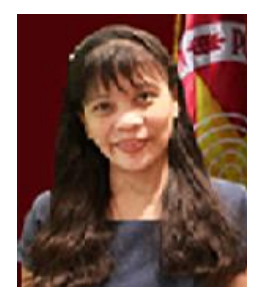

Benilda Eleonor V. Comendador is from Manila, Philippines. Presently, she is the chief of the Open University Learning Management System (OU-LMS) and the program chair of the master of science in information technology (MSIT) of the graduate school of the Polytechnic University of the Philippines (PUP).

She is an associate professor and was the former chairperson of the Department of Information Technology of the College of Computer Management and Information Technology of PUP. She presented several research papers in various international conferences including the (1) 2009 IEICE Society Conference, Niigata Japan; (2) e-Case \& e-Tech in 2010 and in 2012 by International Conference on e-Commerce, e-Administration, e-Society, e-Education, and 
e-Technology, Macau; (3) International Journal of Arts \& Sciences (IJAS) Conference for Academic Disciplines in Las Vegas and (4)The Fifth International Conference on Mobile Computing and Ubiquitous Networking Seattle, U.S.A. She attended various local and international computer related trainings and seminars. She was the country's representative to the Project Management Course in 2005, which was sponsored by the Center for International Computerization Cooperation (CICC) in Tokyo, Japan together with other 9 representatives from various ASEAN countries.

She is a member of Science and Engineering Institutes, Philippine Computer Society and Philippine Schools, Universities, and Colleges
Computer Education and Systems Society (PSUCCESS). She was a grantee of the Japanese Grant Aid for Human Resource Development Scholarship (JDS) from April 2008 to September 2010. She obtained Master of Science in Global Information Telecommunication Studies (MSGITS), major in project research at Waseda University, Tokyo Japan in 2010. She was commended for her exemplary performance in completing the said degree from JDS. She finished her Master of Science in Information Technology at Ateneo Information Technology Institute, Philippines in 2002. 